\title{
CONSTRUCCIONES DEL LENGUAJE DEL VINO EN ESPAÑOL Y EN FRANCÉS
}

\author{
Montserrat Planelles Iváñez \\ Universidad de Alicante
}

\begin{abstract}
RESUMEN: De todos es conocido el auge del enoturismo en la cultura del ocio de la sociedad occidental. Esta actividad, con todas sus manifestaciones, tiene implicaciones directas sobre el lenguaje utilizado, sobre todo, en la crítica enológica. Una de las controversias existentes es la de considerarlo como un lenguaje especifico, que lo convierte en sociolecto, o como un lenguaje pseudoliterario prolijo en metáforas. En cualquiera de los casos resulta incomprensible o al menos extraño para el público no iniciado. De este modo, adjetivos como corto o largo -long, court-, masculino o femenino -masculin, féminin-, corpulento o delgado-corpulent, maigre-, aplicados al vino, resultan oscuros si no se conoce el significado acuñado en el ámbito de la crítica enológica. Me propongo analizar las características de este tipo de textos, que suelen ser breves, nominales, con escasez de verbos conjugados, con proliferación de adjetivos especificos y de ciertas expresiones y construcciones propias del lenguaje del vino. Analizaré asimismo el tipo de verbos que les acompañan. Y todo ello desde una perspectiva comparativa español-francés.
\end{abstract}

PALABRAS CLAVE: Crítica enológica, lenguaje del vino, vocabulario especifico, sintaxis.

\section{CONSTRUCTIONS DU LANGAGE DU VIN EN ESPAGNOL ET EN FRANÇAIS}

\begin{abstract}
RÉSUMÉ: L'essort de l'œnotourisme dans la culture des loisirs de la société occidentale est incontestable. Cette activité, avec toutes ses manifestations, a des implication directes sur la langue utilisée, notamment dans la critique æenologique. Il existe la querelle de considérer cette langue comme une langue spécifique, c'est-à-dire, comme un sociolecte, ou bien comme un langage pseudo-littéraire où les métaphores sont abondantes. En tout cas, le langage s'avère incompréhensible ou bizarre pour un public non initié. Ainsi, des adjectifs tels que corto ou largo -long, court-, masculino ou femenino-masculin, féminin-, corpulento ou delgado-corpulent, maigre-, appliqués au vin, s'avèrent obscurs si l'on n'en connaît pas le sens adopté dans le domaine de la
\end{abstract}


critique onologique. Mon but consite à analyser les caractéristiques de ce type de textes, qui sont d'habitude brefs, nominaux, sans verbe conjugué, avec beaucoup d'adjectifs spécifiques et de certaines expressions et constructions propres du langage du vin. J'analyserai aussi le type de verbes utilisés. Et tout cela dans une prespective comparative espagnol-français.

MOTS CLÉS: Critique oenologique, langage du vin, vocabulaire spécifique, syntaxe.

\section{Introducción}

De todos es conocido el creciente auge del enoturismo en la cultura del ocio de la sociedad occidental, cuyo escenario no solo se encuentra en el entorno rural de las bodegas sino también en los grandes restaurantes con un carácter marcadamente urbano y en ocasiones sofisticado, ya estén vinculados a una ruta de vino o a una bodega o simplemente tengan una cultura del vino arraigada y posean, por ejemplo, un servicio de sumiller experimentado. Esta actividad específica con todas sus manifestaciones -turismo enológico, cata de vinos, cultura del vino- tiene implicaciones directas sobre el lenguaje utilizado, sobre todo, en la crítica enológica. Una de las controversias existentes en este sentido es la de considerar este lenguaje como un lenguaje específico, que lo convierte en sociolecto, o como un lenguaje pseudoliterario prolijo en metáforas. Como esta polémica escapa al objeto de este estudio, solo afirmaremos que ya sea un lenguaje específico con fines comerciales, como el que aparece en las notas de cata o en las propias etiquetas, ya se trate de un discurso pseudoliterario, como ocurre en los artículos de opinión de revistas especializadas, en cualquiera de los casos, resulta incomprensible o al menos extraño, cuando no extravagante, para el público no iniciado.

De este modo, adjetivos como "corto o largo" -long, court-, "masculino o femenino"-masculin, féminin-, "corpulento o delgado"-corpulent, maigre-, aplicados al vino, resultan oscuros si no se conoce el significado acuñado en este ámbito.

En el marco del proyecto de investigación I+D+I FFI2010-19946 ${ }^{1}$ del proyecto de investigación I+D+I Fomenta $2009 / 05^{2}$ me propongo analizar las carac-

1. Este trabajo forma parte del proyecto de investigación FFI2010-19946, financiado por el Ministerio de Ciencia e Innovación, Economía y Competitividad del Gobierno de España que estamos llevando a cabo sobre clases verbales y construcciones sintácticas.

2. El estudio que aquí se presenta se inscribe también dentro del Proyecto FOMENTA 2009/05 de los Planes Riojanos de I+D+I. Convocatoria 2009. Gobierno de La Rioja. Consejería de Educación, 
terísticas de este tipo de textos que suelen ser breves, nominales, con escasez de verbos conjugados, con proliferación de adjetivos específicos y con ciertas expresiones y construcciones peculiares propias del lenguaje del vino. Aunque son escasos, analizaré asimismo el tipo de verbos que les acompañan, "en boca tiene buen ataque", "el ataque en boca parece elegante", que suelen ser predicativos o transitivos, propios de los textos descriptivos. Y todo ello desde una perspectiva comparativa español-francés.

\section{La crítica enológica como crítica del consumo. Características generales de su lenguaje}

Los enólogos y especialistas coinciden en señalar que el vino es un ser vivo. Por consiguiente, cuando tratamos de describirlo o de profundizar en su concepto se pueden abarcar sus múltiples facetas relacionándolo con sus orígenes en la naturaleza, con el campo y la tierra, con el paisaje y su geografía. De este modo, el vino nos habla también del clima, de la historia de la humanidad, de la arquitectura y de la literatura, de las tradiciones culturales e incluso de los contactos entre las civilizaciones. Y es porque este fruto de la naturaleza, sublime a la vez que sabroso, ha fascinado al hombre a lo largo de la historia de la humanidad, por sus múltiples colores, por sus aromas y sus sabores y por su capacidad de evolucionar a lo largo del tiempo. Decir que un vino es bueno, o que es tinto o blanco resulta, por consiguiente, reductivo. Por eso, los especialistas en crítica enológica, al intentar describir los matices del color de un vino, de sus aromas y sabores, no pueden evitar el recurso obligado a las más variadas metáforas (Quero 2008: 207-208).

Armentia (2005: 91-92) observa y distingue dos aspectos en la lengua de la crítica enológica: el literario y el técnico. Por un lado, cada crítico, en el momento de valorar o describir las características del vino, acostumbra a emplear un lenguaje atractivo para calificar de una manera adecuada el producto analizado. Este nivel de la actividad periodística es denominado por los expertos "estilística", plano en el que el autor utiliza todos los recursos de estilo a su alcance, para transmitir de una manera más o menos informativa, explicativa e interpretativa contenidos determinados. Es la fase de la elaboración lingüística del discurso, la elocutio o fase consagrada a los verba. En esta fase el crítico debe seguir no solo las normas de la

Cultura y Deporte, que estamos llevando a cabo sobre el valor comunicativo de las "Nuevas Etiquetas del Rioja" en su comparativa con la etiqueta bordelesa. 
gramática como ars dicendi sino también las de la retórica como ars bene dicendi, que garantizan la eficacia persuasiva y estética del discurso.

De este modo, los estilos utilizados varían según el tipo de crítica de que se trate. Por ejemplo, en la "crítica artística y cultural", el autor se encuentra frente a una obra de naturaleza creativa y en cierto modo, influenciado por ese carácter creativo en el momento de elaborar un juicio de valor. Frecuentemente emplea un lenguaje de cierto nivel literario, con una adjetivación cuidada en las descripciones, con numerosas figuras de retórica, con alusiones a otros campos semánticos. Sin embargo, en lo que llamamos "crítica del consumo", es decir, de un producto industrial, el autor emplea a menudo un lenguaje más directo y menos elaborado y se convierte más bien en un "consejero" de consulta obligada para el lector sobre el producto de consumo, que ejerce una influencia decisiva sobre su opinión antes de comprar o de consumir ese producto.

La crítica enológica se incluye sin duda en el grupo de la "crítica del consumo", puesto que el vino es un producto elaborado para ser consumido, pero también observamos características propias de la crítica artística, como la alusión a otros campos semánticos, la adjetivación prolija y cuidada o la utilización de figuras estilísticas como las metáforas, las personificaciones y las metonimias.

Una vez determinado el tipo de crítica que vamos a analizar, el segundo aspecto que debemos tener en cuenta es el uso de tecnicismos y su adjetivación (Armentia, 2005: 93), cuyo significado suele resultar oscuro para el público no iniciado en el mundo de la enología.

\section{Tipología textual, observación y descripción del corpus}

Nos proponemos observar el lenguaje utilizado en el discurso de la crítica enológica considerada como cata profesional con fines comerciales en dos tipos de textos: por una parte, en textos de cata propiamente dicha, y por otra, en textos de opinión. Las fuentes consultadas son las páginas web www.mivino.info y www.portalgastronomico.com para el español y los suplementos consagrados al vino de las ediciones digitales de Le point y L'Express para el francés.

Existen distintos tipos de cata o degustación. La cata analítica describe el cuerpo y el equilibrio del vino mientras que la degustación hedonista describe el placer que se experimenta cuando se degusta el vino. La degustación de preferencia o de aceptación persigue realizar estudios de mercado entre los consumidores. Podríamos 
añadir otros tipos de crítica, como la anglosajona, la científica, la periodística o la literaria pero esto excede el marco de nuestro trabajo. Nuestro análisis se basará en la observación de textos de la cata profesional, valoración más bien técnica, y en textos del crítico enológico, que se presentan normalmente en un marco periodístico o mediático y que en ocasiones tiene pinceladas literarias.

La tipología textual es diferente: los textos de la cata son breves, precisos, nominales, sin verbos y técnicos, mientras que los textos de opinión son más largos, con frases verbales, más elaborados y literarios, en los que proliferan las metáforas y las frases subordinadas. Pero también tienen características comunes: el autor es especializado en ambos casos, sumiller o crítico, el receptor es asimismo un público especialista o por lo menos conocedor del medio. Los textos son de tipología descriptiva y por ello se caracterizan por la abundancia de adjetivos descriptivos de las sensaciones de color, aroma y sabor que producen los vinos en cada una de las fases de la cata, así como por la presencia de palabras técnicas y de una evaluación final.

Como la degustación o cata del profesional tiene una finalidad comercial, los textos son técnicos y apreciativos a la vez, es decir, analíticos y valorativos, ya que describen las características del vino, analizándolo según las sensaciones que provoca, para emitir una apreciación o juicio de valor. Se trata por tanto de textos que presentan un "análisis sensorial". "Catar" - déguster- es beber, pero analizando las impresiones en cada uno de los órganos que intervienen en el proceso de la degustación: la vista, el olfato y el gusto. Dicho de otro modo, la cata - dégustation- consiste en un análisis sensorial -analyse sensorielle- al mismo tiempo que organoléptico - analyse organoleptique-. La degustación se realiza con los sentidos: la vista, el olfato y el gusto y por consiguiente, la subjetividad del catador está presente en su expresión, de manera que la objetividad de la descripción está matizada por la sensibilidad personal del crítico.

Así pues, el estudio de las fases de la cata es muy importante para nuestro análisis, dado que la descripción del vino se hará por orden de sensaciones y que el lenguaje utilizado deberá expresar, de la manera más exacta posible, las características visuales, olfativas y gustativas del vino objeto de análisis (Sacha González 2006: 80). Los textos serán, por tanto, descriptivos, analíticos, técnicos y apreciativos o valorativos y contendrán las características propias de su tipología.

\section{Vocabulario, construcciones y usos peculiares del lenguaje de la cata}

Hemos observado numerosas expresiones peculiares y específicas del lenguaje del vino tanto en los textos de cata como en los de opinión. Predominan los 
usos nominales de estas palabras acompañadas de adjetivos específicos. En contadas ocasiones se dejan acompañar de verbos. Veamos los ejemplos según las fases de la degustación.

\subsection{El lenguaje de la fase visual}

El aspecto del vino es fácilmente descriptible gracias a la objetividad de los colores y de las texturas: el rojo es rojo, el verde es verde y el amarillo es amarillo. Los matices se expresan a menudo de una manera poética, mediante metáforas del tipo "brillante color caoba con tonos cobrizos y fondo rubi" o "brillante color amarillo pajizo". Pero en esta fase no solo se analiza el color -la couleur-sino también, el brillo -l'éclat-, la viscosidad o las lágrimas, las piernas -la viscosité, les larmes, les jambes-, la limpidez -la limpidité- o la transparencia -la transparence-, la capa -la robe-, y la efervescencia -l'éfervescence- (Sacha González 2006 : 80). Observamos entre estos términos algunos que pueden parecer de significado oscuro en este contexto. Por ejemplo, en español se habla de "las piernas, las lágrimas del vino", así como de la "capa" y en francés, paralelamente, también se alude a "les larmes, les jambes du vin" o la "robe".

Las "lágrimas o piernas" -larmes, jambes- representan la expresión metafórica de la viscosidad del vino. En este sentido, en los textos concurren los términos técnicos -viscosidad, viscosité- con los metafóricos-lágrimas, piernas, larmes, jambes-. Por ejemplo, "Rojo picota, violáceo, cubierto y con lágrima teñida" concurre con "Rojo picota, violáceo, cubierto y con cuerpo viscoso". Raramente aparecen estos sustantivos en frases verbales pero, si lo hacen, los verbos suelen ser transitivos: "dejar lágrimas en la copa" "este vino deja una lágrima viscosa", "laisser des larmes sur le verre" o "tener lágrima teñida", siendo "lágrima o pierna" "larme o jambe" el objeto directo del verbo. Hemos atestado usos con verbos intransitivos del tipo "formarse" o "couler", actuando "las lágrimas" o "les larmes" como sujeto: "Al agitar la copa nuevamente y con suavidad se comprueba, a trasluz, cómo se forman las lágrimas del vino" "des larmes coulent lentement...".

Por su parte, con el término "capa" - robe- nos referimos a la limpidez, el brillo y la intensidad. Estos usos metafóricos revelan en el fondo, en el contexto de la semántica cognitiva (Lakoff y Johnson: 1980), la metáfora conceptual del tratamiento del vino como un ser vivo, incluso como una persona. En este sentido, se describen las cualidades visuales del vino como si de una persona se tratara y estos sustantivos se hacen acompañar de adjetivos muy variados cuya elección se inserta 
asimismo en dicha metáfora conceptual, que subyace en el contexto de la descripción del vino, cuyo significado, lejos de ser subjetivo, resulta especialmente preciso y técnico además de ser comúnmente aceptado por los especialistas y conocedores de este ámbito. Se dice que un vino "tiene más capa, tiene capa alta" si es más oscuro y que "tiene menos capa" si es más claro. En este tipo de textos descriptivos, "capa" suele aparecer en frases nominales, sin verbo, la mayoría de las veces con la función de complemento del nombre "color" y calificados por adjetivos bien precisos: "Excelente color rojo picota, capa alta y lágrima teñida", "Bonito color picota con tonos cárdenos, de capa media", "Bonito color picota con tonos cárdenos, de capa media", "Excelente expresión del color, rojo picota, de capa media-alta, vivo y atractivo" "El color rojo cereza y de capa media es muy atractivo", "Color cereza de capa alta y borde violáceo".

En francés se habla de "la robe du vin" con un sentido más amplio que "capa", para aludir tanto al color como a la intensidad conjuntamente: "Robe: or clair, brillant." "Jacquère à la robe doré pâle" "Une robe noire, profonde et dense", "Robe dense" "Robe: profonde, peu évoluée". El sustantivo "robe" aparece utilizado nominalmente con adjetivos concretos, como en los ejemplos anteriores, o bien con el verbo "avoir": "Ce vin limpide $a$ une robe jaune très claire, éclatante et rafraîchissante”. En textos de opinión las frases son más elaboradas $\mathrm{y}$ verbales, por lo que se observan usos verbales cuyo significado indica que nos encontramos inmersos en la metáfora conceptual de la personificación del vino: "La robe orangée très claire annonce un corps de grande finesse", "Vêtu d'une très belle robe pourpre".

\subsection{El lenguaje de la fase olfativa}

El análisis olfativo del vino se realiza por dos vías: la nasal y la retronasal (Sacha González 2006: 81). Esta fase es más subjetiva que la anterior pues los olores son intangibles. Si alguno de nosotros nos dice que un vino huele a manzana ¿quién puede negarlo? En español se habla de "la nariz del vino", del mismo modo que en francés se alude a "le nez du vin". "Nariz" -nez- en este contexto es sinónimo de olor, de aroma-odeur, arôme-. Hay que señalar que los especialistas, profesionales y amantes del vino no suelen utilizar la palabra "olor" -odeur-porque tiene un matiz peyorativo. Hablan más bien de "nariz" o de "aroma" -nez, arôme-. Esta alusión a la "nariz" -le nez- es muy frecuente en los textos descriptivos de los vinos tanto de cata como de opinión: "vino de gran nariz" significa "vino de aroma intenso". "Percibir hierbas en la nariz del vino" significa que el vino huele -o sabe- a hierbas. "Chocolat, menthe au nez" significa que el vino 
huele a chocolate y menta. "Grillé, moka, épices, nez pas encore complètement développé": el vino no tiene un aroma todavía definido. Cabe añadir un nuevo término frecuentemente utilizado: el galicismo adaptado al español "buqué" -bouquet-: "Su incipiente buqué resulta ya complejo" "De su seductor e incipiente buqué destacan los aromas de frambuesa, de casis, las notas especiadas y un sutil toque mineral", "su buqué está bien sostenido con finos aromas de frutillos de bosque, un claro toque especiado y mineral, con un recuerdo de caja de puros y cacao".

En la mayoría de los ejemplos de nuestro corpus estos sustantivos aparecen en frases telegráficas y nominales, acompañados de adjetivos concretos y con construcciones diferentes en función del significado de "nariz" o "nez":

En primer lugar, "nariz" aparece con frecuencia la locución preposicional "en nariz". Con esta locución se expresa el órgano en el que se producen las sensaciones la fase olfativa. La construcción observada es específica del lenguaje del vino, pues en el lenguaje general, el sustantivo debería ir acompañado del artículo "en la nariz". Así pues, en nuestro corpus hemos atestado este uso en frases nominales: "Muy complejo en nariz, sobresalen los aromas de maderas nobles, de nueces, almendras y avellanas tostadas, de orejones, junto a los atrayentes recuerdos marinos", pero también en frases verbales, con el verbo copulativo "ser" y verbos del tipo "desarrollarse", que precisan de un sujeto en evolución como lo es el vino, seguido de los adjetivos descriptivos de los aromas: "En nariz (el vino) es fragante, se desarrolla como una explosión de frutillos de bosque (frambuesas, arándanos, grosellas), notas balsámicas y recuerdos tostados", o con verbos transitivos como "ofrecer" o destacar", que precisan completar su significado con sustantivos como "aroma" o "buqué" acompañados de los consiguientes adjetivos calificativos del aroma específico: "(el vino) Ofrece en nariz aromas de frutillos de bosque", "En nariz destaca un paso aromático en el que los acentos frutales tienen protagonismo".

Con este mismo significado aparece también sin preposición, aunque es un uso más raro, debido más bien a las licencias estilísticas que se permiten los críticos en sus catas y artículos: "Igual de inquieta y bulliciosa se muestra la nariz: aromas de frutillos de bosque limpios y potentes, también delicadas notas florales, un fondo de regaliz".

En segundo lugar, encontramos el término "nariz" en complementos de nombre introducidos por la preposición "de": "Vuelven los aromas de nariz a la retronasal, aunque bien acompañados por su limpio final de cítricos", "lleva a un final realmente impactante, donde a los aromas de nariz se añaden bellas notas balsámicas". Nos en- 
contramos de nuevo ante una expresión específica del lenguaje del vino, que resulta a primera vista redundante, pues los aromas no pueden ser de otra naturaleza que "de nariz", pero que en este contexto no lo es, pues con esta expresión se especifica que los aromas descritos son los que se experimentan en la fase olfativa, distinta y previa a la gustativa, en la que también se habla de "aromas" como sinónimo de "sabores".

En tercer lugar, hemos registrado usos técnicos polisémicos de "nariz", con el significado, en estos casos, de "características olfativas del vino": "Un color atractivo, amarillo verdoso y muy vivo abre perspectivas a una nariz compleja, donde se funden los aromas de fruta carnosa, de manzana y flores con las notas de hierbas aromáticas, hinojo, piel de cítricos y especias", "Desde el primer sorbo muestra su disposición a la limpieza, a los frutillos rojos como hilo conductor de una nariz sugerente repleta de matices".

En lo que a "nez" se refiere, observamos usos paralelos a los del español. En primer lugar, la locución "au nez" expresa el órgano en el que se experimentan las características olfativas: "Chocolat, menthe au nez, bouche ronde, épicée, assez virile mais sans dureté, très persistante, des accents de pauillac", "Doré franc, assez fermé au nez".

Los usos nominales son abundantes, con el significado de "características olfativas": "Nez fin, mentholé, pamplemousse, savoureux, minéral, fondu, joli potentiel, note d'amertume", "Nez confit, fruits secs, amande, ananas, onctueux, équilibré, long, mineral", "Nez: net, fruité, finement boisé et fumé. Jolie complexité", "Nez: ananas confit, miel, abricot confit". Aunque también se usa como sujeto del verbo être: "Le nez est élégant, très pur, avec une note de grillé". Como ocurre en español, en los artículos de opinión también aparece con frecuencia en frases verbales con verbos como "se mêler", "offrir" o "avoir": "La cerise noire et la violette se mêlent de la façon la plus élégante dans un nez de grand style", "Doré pâle, cette jacquère offre un nez vineux, capiteux, mûr", "Doré pâle, cette altesse offre un nez aromatique, opulent, atypique de melon, abricot, très mûr".

\subsection{El lenguaje de la fase gustativa}

En la fase gustativa, los sabores y los aromas de mezclan. El vino es "dulce, ácido o amargo". La riqueza de adjetivos en esta fase es espectacular y ello se debe a la riqueza de los sabores y de los aromas. Así, se asocian al vino sabores de frutas, de hierbas aromáticas, de verduras, de tierra, de flores, de hierba fresca, de hoja de tabaco, de pan tostado, de humo, de café o de chocolate. 
Cuando se dice que un vino es "dulce, seco o semiseco" se hace alusión al sabor más o menos dulce del vino. En este sentido, el único adjetivo utilizado en sentido propio es "dulce", porque "seco o semiseco" en la lengua general significa lo relativo a la falta de humedad y además se refiere a la textura y no al sabor. He aquí, por tanto, un adjetivo que ha adquirido una nueva acepción en este discurso específico y que, por consiguiente, puede resultar incomprensible para el público no iniciado. Por otra parte, cuando se dice que un vino es "fresco" se quiere expresar que tiene un buen equilibrio de acidez, mientras que un vino "pesado" significa lo contrario. Como en el caso de "seco o semiseco", los adjetivos "fresco y pesado" adquieren significados nuevos y específicos en el contexto de la crítica enológica.

Esta fase resulta ser más compleja que las anteriores, pues no solo se evalúa el sabor o el aroma sino también el "tanino" -le tannin-, palabra técnica que denomina la substancia orgánica contenida en la piel y en las pepitas de la uva. Los niveles de tanino determinan también el grado del sabor amargo y así, en función de los niveles de tanino, un vino es "astringente, duro, aterciopelado o suave". Es astringente o duro cuando contiene un exceso de taninos. Se dice que es "duro" también cuando hay un alto grado de acidez y en este caso el adjetivo es polisémico. Y al contrario: un vino es "suave" o "aterciopelado" cuando los taninos son casi inexistentes. En este sentido, nos encontramos con otro ejemplo de adjetivo que cambia de significado en el paso del discurso general al discurso especializado: "aterciopelado" es una metáfora de la suavidad, sinónimo en este caso de "suave" - doux-, siendo su sentido propio "de finura y suavidad semejantes al terciopelo".

"Astringente, duro y suave" se utilizan con el mismo sentido general que en la lengua corriente o al menos con alguna de sus acepciones, como en el caso de "duro", cuyo sentido principal alude a la textura dura de un objeto que impide que sea rayado o arañado y en el contexto de la descripción del vino su significado se acerca más a la acepción que alude a la cualidad rugosa o áspera de una superficie. Las cualidades de suavidad o de dureza, en este contexto, se refieren a las "impresiones de textura transmitidas en el momento de la degustación del vino".

En esta fase encontramos la alusión al cuerpo del vino -le corps du vin-. Algunos vinos dan una impresión de plenitud, incluso de peso, se dice que "se pueden masticar" - mâcher-, otros son ligeros, de menor densidad. Así, el vino tiene "un cuerpo ligero, un cuerpo medio o pleno, carnoso, o voluminoso". "En boca resulta pleno y sabroso", "Vin élégant, fin au corps charnu et soyeux", "un corps ample et une très belle longueur". De nuevo nos encontramos frente a sustantivos 
y adjetivos utilizados de manera metafórica porque es evidente que los vinos no tienen cuerpo sino densidad, es decir, son más o menos fluidos. La metáfora comienza en la comparación de la densidad con el cuerpo, y los adjetivos descriptivos se aplican, por consiguiente, al "cuerpo imaginario del vino" que permite interpretar sus características en términos de cantidades concretas como si de un cuerpo sólido se tratase. No se diría nunca del agua, por ejemplo, que es "carnosa" -charnue-o "voluminosa"-volumineuse-.

Como hemos afirmado más arriba, en esta fase gustativa, los aromas de mezclan, pues el olfato se pone en acción también durante la degustación y está en contacto permanente con la cavidad bucal. En efecto, los especialistas prefieren hablar de "familias de aromas" para describir los aromas y los sabores del vino. Y en este sentido, todas las comparaciones y metáforas son admitidas. Si el vino es afrutado, puede oler y saber a "frutas maduras, peras, albaricoque y recuerdos exóticos como el lichi, a lo que se añaden sutiles tonos florales y un buen equilibrio fruta/madera" "surgen como manantial sus frutillos del bosque, recuerdos de regaliz y notas especiadas con la madera muy bien integrada". Si el vino es "terroso" -terreux-, sabe a "setas" - champignons-, "a tierra removida", "a hojas secas" feuilles sèches- ; puede ser también especiado o de hierbas: "Un color atractivo, amarillo verdoso y muy vivo abre perspectivas a una nariz compleja, donde se funden los aromas de fruta carnosa, de manzana y flores con las notas de hierbas aromáticas, hinojo, piel de cítricos y especias", "Biscuit, épices, fruits noirs, souple, soyeux, assez joli boisé, élégant".

En definitiva, todo un universo de sensaciones casi infinitas, que dependen de la sensibilidad del especialista y a veces de su habilidad con el lenguaje: "El final se balancea entre la pátina pizarrosa y el toque de cacao -o mejor chocolate amargo-, pero tan fino y leve que incita a repetir la experiencia inmediatamente", "Los originales aromas de este Monastrell se acercan más a los frutillos silvestres (mora, frambuesa) que a los de algarroba -caroube- o higos, lo que aporta sensación de frescura; hay recuerdos tostados y especiados, y un toque mineral".

En la fase gustativa son las palabras "boca" - bouche- (ataque en boca, attaque en bouche) las que aparecen en diversas expresiones y locuciones. También se alude al "cuerpo" del vino - le corps $d u$ vin- o al "recorrido del vino". Pero centrémonos en "boca" y "bouche".

Observamos usos polisémicos de estos sustantivos, como en el caso de "nariz" y “nez". Al mismo tiempo, las expresiones muestran paralelismos semánticos y 
sintácticos. Así, "boca" y "bouche" aparecen en locuciones como "En boca/en la boca" y "en bouche", significando el órgano en el que se experimentan las sensaciones gustativas que provoca el vino en el proceso de la cata. Las frases suelen ser nominales: "En boca fruta ácida, mineral, cola, cacao, cerezas, guindas, un poco secante", "En boca mucha cola, fruta roja, tanicidad, algo secante, cacao, café, buena acidez", "En boca café con leche, azúcar glass, manteca, fruta azul, yougur de fresa-frutos del bosque", pero también se usan las expresiones en frases verbales, con verbos del tipo "ser", "resultar", "mostrarse", "sorprender", "tener, "apreciarse", "discurrir", "mantener": "Es sabroso, muy fresco y alegre en boca", "sorprende en boca por su frescura, su inmediatez, su viveza y armonía", "Se aprecia amable y untuoso en boca", "en boca es mineral, aromático y frutoso", "En boca tiene una estructura media", "En la boca es sabroso, bien estructurado, con un tanino maduro y delicioso que aporta carnosidad", "En la boca resulta goloso, muy suave, de un tanino tan sedoso como un guante de terciopelo", "En la boca es armonioso, discurre con carnosidad y amplitud, un toque goloso le aporta esa untuosidad que llena el paladar", "en boca mantiene esa fruta", "en boca se muestra con potencia y resalta la fruta madura", "En boca tiene una entrada muy intensa, fruta negra y azul, pimientas, taninos dulces, amargor agradable, cacao en polvo". En todos estos casos el sujeto implícito es "el vino" y la expresión "en boca" funciona como locativo.

La expresión "paso de boca" es una unidad léxica compuesta que adquiere un significado muy preciso y técnico en el lenguaje del vino. Significa, según Wiesenthal (2001: 628) las impresiones que deja un vino en su discurrir por el paladar y se sitúa entre el ataque y el final de boca, es decir, se considera la fase central de la degustación. En este instante se perciben tanto la forma y estructura del vino como su constitución tánica y su cuerpo. Los verbos que aparecen con esta expresión son "desarrollarse", "tener", "ampliarse", entre otros, siendo "paso de boca" el sujeto, el objeto directo o el locativo, pero lo más habitual es dejarse acompañar por adjetivos descriptivos de las sensaciones determinadas y precisas que provoca el vino en esta fase: "Paso de boca que se desarrolla con profundidad", "En su amplio paso de boca se puede apreciar el tono salino y un recuerdo amargo que aporta elegancia", "Tiene en el paso de boca un excelente balance, entre la golosidad, lo ácido y lo floral", "se amplía con poderío en el paso de boca", "Tiene un paso de boca fresco y vivo".

En lo que al francés se refiere, los usos son comparables al español. Por un lado, aparece la locución preposicional "en bouche" precedida de los adjetivos descriptivos de las sensaciones gustativas: "rond en bouche, suave, puissant, riche, tanins vifs", "velouté en bouche", "paraît plus jeune en bouche qu'au nez". Tam- 
bién se usa "la bouche", significando en ambas expresiones el órgano en el que se experimentan las sensaciones gustativas: "La cerise noire et la violette se mêlent de la façon la plus élégante dans un nez de grand style, la bouche confirme cette excellente impression avec des tanins longs, frais et précis, superbe réussite".

El significado de "características gustativas del vino" se encuentra en los siguientes ejemplos: "Délicat et frais, le nez délivre des flaveurs de pamplemousse et d'iode, la bouche est franche et fraîche, bel équilibre", "Le nez est fruité, élégant, rappelant la confiture de mûre et la myrtille, avec une pointe torréfiée de grande élégance, la bouche charnue et musclée, tout en puissance mais avec un tanin ferme et un grand fond", "bouche soyeuse en attaque".

Finalmente, tras el análisis exhaustivo de las cualidades visuales, olfativas y gustativas del vino, llega el momento de opinar sobre su calidad. En este momento se habla del "final del vino"-la finale du vin, la fin de bouche-. El vino debe reunir las condiciones adecuadas de "equilibrio -équilibre-, longitud -longueur-, profundidad -profondeur-, complejidad -complexité-" que resultan misteriosas aplicadas al vino. El final de un vino es "largo" -long- o "corto" - court-: "su final, entre el gusto goloso y el elegantemente amargo, es largo, muy largo ", "Charnel, légèrement vanillé, sanguin, bouche élégante, souple, bien fruité, large et fin, long, plein" o "pleno" -plein-: "Tiene un final espléndido, pleno de fruta y armonía", "Jolie texture fruitée, équilibrée, finale bien pleine" o "equilibrado"-équilibré-.

El significado de largo o corto como característica del vino es específico y debe ser explicado al público no entendido. La longitud -la longueur-son términos que se utilizan para describir que un vino se cata o se degusta a lo largo de todo el paladar, o bien, se queda a medio camino en el proceso de la degustación. Así, el vino es "corto" -court-o "largo" -long-. Ocurre lo mismo con la profundidad: una persona ajena al mundo del vino no puede saber que un vino "plano" - plain- es un vino desequilibrado a causa de la falta de acidez y que, por el contrario, un vino "profundo" - profond- es un vino equilibrado en su grado de acidez. Estos adjetivos, en el discurso de la cata o degustación, adquieren un significado especializado.

En este momento se recurre, como hemos afirmado, a los sustantivos "final (de boca/del vino)" y "finale (de bouche/du vin)". En el lenguaje de la degustación, estos sustantivos adquieren un significado preciso, técnico y unívoco. Indican el conjunto de sensaciones que deja el vino en la boca, después de haber desarrollado todo su paso de boca impresionando las papilas y el paladar y después de expresar su postgusto en vía retronasal. En este sentido "final (de boca/del vino) 
es sinónimo los términos "longitud (en boca)"-longueur (en bouche)- y "persistencia" - persistance-. Como en los casos anteriores, los adjetivos descriptivos de la persistencia gustativa acompañan necesariamente a estas expresiones. Los usos nominales concurren con los verbales, siendo los verbos más habituales "ser" être-, además de los verbos transitivos "dejar" -laisser-, "tener" - avoir-, "mantener" - maintenir-, actuando como objeto directo o sujeto: "con un final rico en matices de aromas frutosos, regaliz y hierbas aromáticas", "en boca es mineral, aromático y frutoso, sabroso final", "su final, entre el gusto goloso y el elegantemente amargo, es largo, muy largo, "El final es aromático, profundo, con un gustoso recuerdo de regaliz", "Un final pleno de aromas deja un excelente sabor de boca", "Tiene un final espléndido, pleno de fruta y armonía", "En boca tiene una estructura media, con buena acidez, fino fresco, con frutos secos y alguna nota especiada y un buen final".

En los textos de opinión, de estilo más elaborado y libre, aparece con verbos transitivos que se podrían sustituir por "tener": "Tiene un paso de boca fresco y vivo, es amable, jugoso y de amplio discurrir, y regala un final elegante y aromático".

La locución preposicional "al final" es propia de estos textos: "Amplio y untuoso, al final deja una fina sensación aromática"

Cabe señalar el uso adjetival de "final", que tiene en este contexto un significado preciso, expresando justamente la sensación o persistencia gustativa en la última fase de la degustación. "Sensación de finura y elegancia final, con recuerdos de jengibre", "Explosión aromática final", "En boca mucha fruta (negra-azul), intenso, violetas, taninos dulces y pulidos, amargor final".

Los usos en francés son paralelos. Normalmente aparece en frases nominales: "tanins vifs mais finale un peu sèche", "Finale à la tannicité légèrement apparente", en la locución "en finale": "une pointe de sec en finale", "Vanillé, séduisant, bouche ronde, gourmande, assez fine, souple, très beau fruit en finale", "Les tanins sont fondus en finale" y como adjetivo: "Matière élégante, délicate, expressive, belle acidité finale".

\section{Conclusión}

Tras la observación y análisis del corpus, tanto el vocabulario como las expresiones peculiares encontradas en los textos de cata y de opinión no hacen sino confirmar que el lenguaje del vino es específico y especializado. 
En el uso de los adjetivos y de los sustantivos propios de la descripción del vino subyace una metáfora conceptual que demuestra que su elección no es arbitraria sino que responde a una idea profundamente arraigada en la tradición vitivinícola y enológica, de considerar el vino como un ser vivo y sublime, incluso en ocasiones comparable al ser humano en todo su esplendor. Esta especie de convención subyacente, comúnmente aceptada por todos, convierte el lenguaje del vino en un sociolecto, solamente comprensible en su totalidad por los conocedores y especialistas en la materia.

Los textos analizados son de tipología descriptiva, analíticos, técnicos y valorativos o apreciativos, con características propias del discurso de la crítica del consumo. En ellos observamos no solo un vocabulario propio y específico sino también unas expresiones y locuciones que muestran paralelismos léxicos, semánticos y sintácticos en las en las dos lenguas comparadas: por ejemplo, "en boca" y "en nariz" (esp.) y "en bouche" y "au nez" (fr.), actuando en las frases como locativos. Dichas expresiones peculiares responden a usos metafóricos de unidades léxicas que adquieren un significado específico en el discurso de la crítica enológica y que concurren con sus sinónimos técnicos: "lágrimas o piernas" -larmes o jambes - conviven con "viscosidad" -viscosité-, "capa" - o robe- lo hacen con limpidez, brillo o intensidad -limpidité, éclat, intensité- y "nariz" y nez con "aroma" -arôme-, por poner algunos ejemplos. En definitiva, todos estos hechos no hacen sino reafirmar las ideas anteriores: la existencia de un lenguaje propio basado en una conciencia común.

\section{Bibliografía}

ARMENTIA, J. I., CAMINOS, J. M. y MARÍN, F. (2005). "El lenguaje de la crítica enológica en la prensa española: El País, El Semanal (Vocento) y Magazine (Godó-Prensa Ibérica)". Zer 19: 89-125.

COUTIER, M. (2007). Dictionnaire de la langue du vin. Paris: CNRS.

COUTIER, M. (1994). "Tropes et termes: le vocabulaire de la dégustation du vin", Meta 39 (4): 662-675.

DEMAECKER, C. (2006). "Les métaphores du vin et leurs traductions" en El lenguaje de la vid y el vino. (Coord. M. Ibáñez y M. T. Sánchez). Valladolid: Universidad de Valladolid, Secretariado de Publicaciones e Intercambio Editorial: 298-303.

L'Express Syles: Vins. <http://www.lexpress.fr/styles/saveurs/vins/> (Acceso septiembre 2011). 
IBÁÑEZ RODRÍGUEZ, M. y SÁNCHEZ NIETO, M. T. (coord.) (2006). El lenguaje de la vid y el vino. Valladolid: Universidad de Valladolid, Secretariado de Publicaciones e Intercambio Editorial.

LAKOFF, G. y JOHNSON, M. (1980). Metáforas de la vida cotidiana. Madrid: Cátedra. Colección Teorema.

LAKOFF, G. y JOHNSON, M. 1985 (1980). Les métaphores dans la vie quotidienne. Paris: Editions de Minuit.

LAKOFF, G. y JOHNSON, M. 2003 (1980). Metaphors We Live by. Chicago y Londres: The University of Chicago Press.

Lepoint.fr-Le guide du vin. <http://www.lepoint.fr/vin/> (Acceso septiembre 2011).

LERAT, P. (2006). "Dénominations spécialisées, connaissances professionnelles et connaissances linguistiques en terminologie. Le cas du vin" en El lenguaje de la vid y el vino. (Coord. M. Ibáñez y M. T. Sánchez). Valladolid: Universidad de Valladolid: 85-99.

LLAMAS SAÍZ, C. (2005). Metáfora y creación léxica. Pamplona: Eunsa.

McCARTHY, E. y EWING-MULLIGAN, M. (2006). Vino para Dummies. Barcelona: Granica.

Mi vino-Vinum. $<$ http://www.mivino.info >. (Acceso septiembre 2011).

NUBIOLA, J. (2000). "El valor cognitivo de las metáforas" en Verdad, bien y belleza. Cuando los filósofos hablan de los valores. (Coord. P. Pérez-Ilzarbe y R. Lázaro). Cuadernos de Anuario Filosófico 103: 73-84.

Portalgastronomico.com. <http://www.portalgastronomico.com> (Acceso septiembre 2011).

QUERO, S. (2008). "La cata y las metáforas". Litoral, El vino, Historia, Arte, Literatura 245: 207-208.

SANCHA GONZÁLEZ, J. C. (2006). "La cata del vino y su terminología" en El lenguaje de la vid y el vino (Coord. M. Ibáñez y M. T. Sánchez). Valladolid: Universidad de Valladolid: 77-84.

VANDAELE, S. y LUBIN, L. (2005). "Approche cognitive de la traduction dans les langues de spécialité: vers une systématisation de la description de la conceptualisation métaphorique. Meta 50 (2): 415-431.

VANDAELE, S. et al. (2006). "La métaphore en biomédecine: indices de conceptualisation et réseaux lexicaux". Glottopol 8: 73-94.

VANDAELE, S. (2009). "Les modes de conceptualisation du vivant: une approche linguistique" en Que peut la métaphore? (Coord. F. Boucher, S. David y J. Przychodzen): 187-207.

WIESENTHAL, M. (2001). Diccionario Salvat del vino. Barcelona: Salvat. 